\title{
PENERAPAN SIX SIGMA PADA PENGENDALIAN KUALITAS PROSES PRODUKSI GOOD DAY CAPPUCINNO
}

\author{
I.G.A Sri Deviyanti, Iman Supriadi \\ Jurusan Teknik Industri \\ Universitas WR.Supratman Surabaya \\ Email : srideviyanti@gmail.com
}

\begin{abstract}
ABSTRAK
$\mathrm{P}$ enelitian ini menggambarkan bagaimana aplikasi metode Six Sigma digunakan untuk melakukan perbaikan kualitas pada perusahaan manufaktur yang memproduksi produk Good day Cappucinno. Pendekatan DMAIC dipakai untuk menganalisa dan melakukan perbaikan produk Good day Cappucinno karena tingginya variabilitas dan cacat dibanding produk lain. Perbaikan kualitas di fokuskan pada proses yang mempengaruhi terjadinya cacat yaitu pada sub proses mixing dan packing. Penentuan proyek Six Sigma didasarkan atas proses dan jenis cacat pada setiap sub proses. Pendekatan FMEA mampu memberi rekomendasi perbaikan kualitas. Evaluasi dari hasil perbaikan penting untuk dilakukan karena beberapa implementasi perbaikan kualitas tidak berjalan sesuai dengan rencana. Pelaksanaan perbaikan kualitas dengan Six Sigma perlu dilakukan secara serentak dan dilakukan penggambaran dan pendefinisian yang sistematis dan keseluruhan agar pemetaan permasalahan kualitas dapat terlihat secara menyuluruh. Usaha ini akan sangat membantu perusahaan didalam membentuk tim-tim Six Sigma di keseluruhan department dan line produksi. Adanya usaha ini akan menyebabkan lingkungan kerja akan semakin kondusif dan budaya "peduli kualitas" akan mudah terbentuk di perusahaan. Dalam perbaikan Good day Cappucinno di PT Santos Jaya Abadi menunjukkan bahwa tidak semua rencana perbaikan mampu menurunkan DPMO atau meningkatkan nilai Sigmanya mungkin karena pelaksanaan perbaikan di lapangan tidak berjalan dengan baik atau kurang efektif. Oleh karena itu penting bagi perusahaan melakukan evaluasi secara berkala untuk memastikan langkah pelaksanaan perbaikan di lapangan benar-benar berjalan dengan baik dan mengikuti prosedur yang telah direncanakan.
\end{abstract}

Kata kunci: Six Sigma, DMAIC, DPMO

\section{PENDAHULUAN}

Awal tahun 1980-an, metode Six Sigma mulai diperkenalkan aplikasinya pada perusahaan manufaktur oleh Motorola dan secara bertahap diaplikasikan juga pada sektor bisnis lain seperti perbankan, hotel, rumah sakit, migas, dan sektor lainnya (Mayor,2003). Tidak hanya Motorola, tetapi masih banyak perusahaan besar seperti General Electric, Texas Instruments, Allied Signal, Eastman Kodak, Borg-Warner Automotive, GenCorp, Navistar International and Siebe plc juga menerapkan Six Sigma (Murphy, 1998).

Pendekatan Six Sigma didasarkan atas teori kualitas Jepang seperti: Total Quality Management (TQM), Kaizen, dan Quality Control Cycle (QCC) yang sering diaplikasikan pada proses manufaktur. Motorola mulai menerapkan Six Sigma pada tahun 1982 ketika program peningkatan kualitas mulai diimplementasikan secara terfokus pada proses manufaktur dengan target mereduksi biaya kualitas sebesar setengahnya. Usaha mereduksi biaya merupakan titik awal untuk melakukan perbaikan dan desain produk secara kontinu dengan memfokuskan pada desain kualitas dan sejumlah tools kualitas yang baru bagi karyawan. Pengembangan tools baru dan membuat kualifikasi Six Sigma yang praktis merupakan usaha awal bagi Motorolla untuk memenangkan Malcolm Baldrige Award pada tahun 1988 (Hendricks and Kelbaugh, 1998).

Dalam konteks Indonesia, aplikasi Six Sigma relatif baru. Banyak perusahaan di Indonesia mengaplikasikan Six Sigma karena perusahaan induk-nya di Amerika dan Eropa telah mengaplikasikannya seperti General Electric Indonesia, Caltex, dan perusahaan lainnya. Tidak hanya perusahaan barat yang mencoba menggunakan Six Sigma, tetapi juga perusahaan Jepang menggunakannya tanpa meninggalkan aplikasi peningkatan kualitas dasarnya, tidak terkecuali perusahaan PT. Santos Jaya Abadi yang memproduksi product Good day Cappucinno. Langkah kerja DMAIC (Define, Measure, Action, Improve, dan Control) merupakan langkah kerja 
yang penting yang perlu dilakukan secara sistematis guna mencapai hasil peningkatan kualitas.

Penelitian ini menggambarkan bagaimana upaya memperbaiki dan meningkatkan kualitas produk Good day Cappucinno di PT Santos Jaya Abadi dengan menggunakan langkah kerja DMAIC pada Six Sigma. Pendekatan yang dilakukan adalah melakukan pengamatan awal dan wawancara untuk menentukan proyek yang akan dilakukan perbaikan. Hasilnya menunjukkan bahwa, sub proses mixing dan packing merupakan titik kritis (CTQ) yang menyebabkan terjadinya cacat produk. Proyek perbaikan pada sub proses mixing dan packing inilah yang akan dipaparkan sebagai proyek yang menggambarkan bagaimana aplikasi langkah kerja DMAIC pada Six Sigma bisa melakukan pencapaian tingkat kualitas yang lebih baik.

Awalnya Six Sigma adalah konsep statistik yang mengukur suatu proses yang berkaitan dengan cacat - pada level enam (six) sigma dengan 3.4 cacat dari sejuta peluang (Brue, 2002). Konsep, alat, dan sistem Six Sigma telah berhasil dikembangkan oleh GE dan Allied Signal/Honeywell seperti big picture mapping, dan Failure Mode Effect Analysis (FMEA). Kedepannya penambahan konsep, alat dan sistem yang dibutuhkan pada Six Sigma akan berperan meningkatkan usaha perbaikan proses dan kualitas sesuai dengan kebutuhan para manager perusahaan.

Aplikasi Six Sigma berfokus pada cacat dan variasi, dimulai dengan mengidentifikasi unsurunsur kritis terhadap kualitas (CTQ) dari suatu proses. Six Sigma menganalisa kemampuan proses dan bertujuan menstabilkannya dengan cara mengurangi atau menghilangkan variasi-variasi. Langkah mengurangi cacat dan variasi dilakukan secara sistematis dengan mendefinisikan, mengukur, menganalisa, memperbaiki, dan mengendalikannya. Langkah sistematis dalam Six Sigma dikenal dengan metode DMAIC. Team Six Sigma didalam menyelesaikan proyek yang spesifik untuk dapat meraih level Six Sigma perlu berpedoman pada 5 fase pada DMAIC tersebut (Paul, 1999).

Fase Define (D) dilakukan pendefinisian proyek dan tujuan yang hendak dicapai berdasarkan keinginan dan feedback pelanggan. CTQ (Critical to Quality) adalah hal yang perlu didefinisikan berdasarkan input dari pelanggan terhadap kualitas yang diinginkan terhadap produk. Fase Measure (M) akan memilih indikator kinerja dan menentukan pengukuran baseline. Six Sigma team harus mengidentifikasi proses internal kunci yang mempengaruhi CTQ dan perlu mengukur cacat yang relevan dengan CTQ dan proses internal kunci-nya. Fase Analyze (A), dilakukan analisa yang mendalam mengenai penyebab utama dari cacat yang terjadi. Team Six Sigma perlu menemukan mengapa cacat terjadi dari hasil identifikasi variable kunci yang menjadi penyebab timbulnya variasi pada proses. Fase Improve (I) akan melakukan upaya perbaikan agar penyebab dari cacat tidak terjadi atau semakin tereduksi. Team Six Sigma perlu mengkonfirmasi variabel kunci, mengkuantifikasi efek dari CTQ ini, dan menjalankan proyek perbaikan. Fase Control (C), dilakukan agar team Six Sigma dan operator dapat memelihara peningkatan kualitas menuju kualitas level 6 (six). (Mayor, 2003)

\section{METODE}

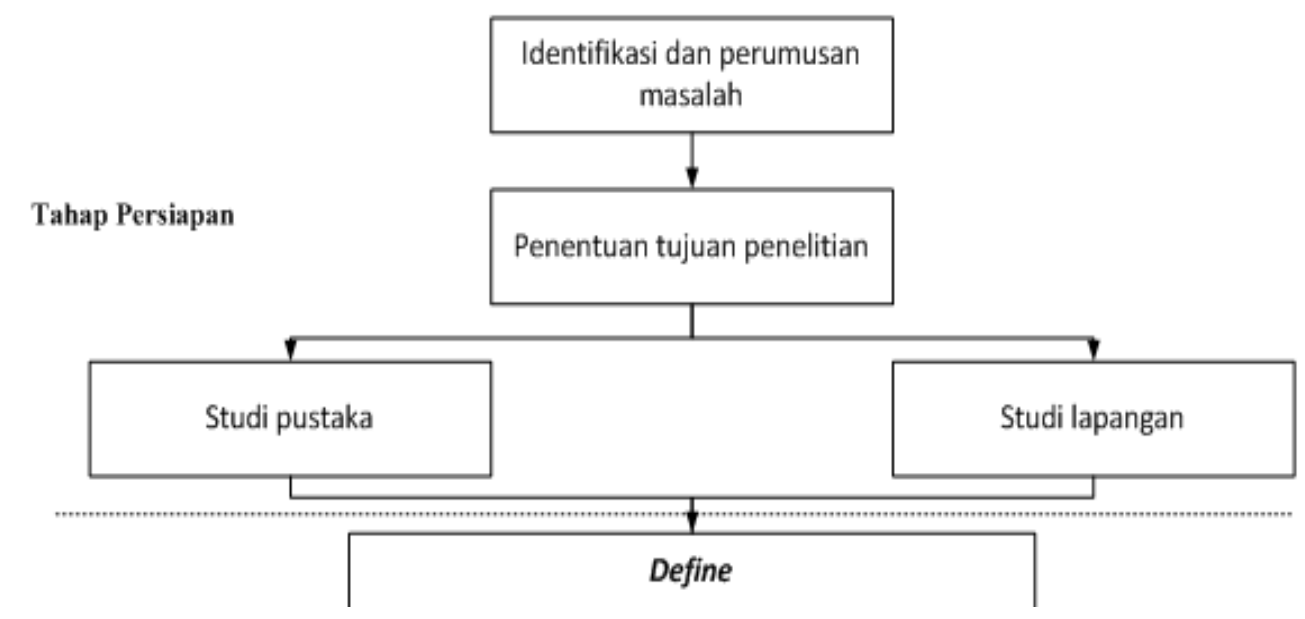




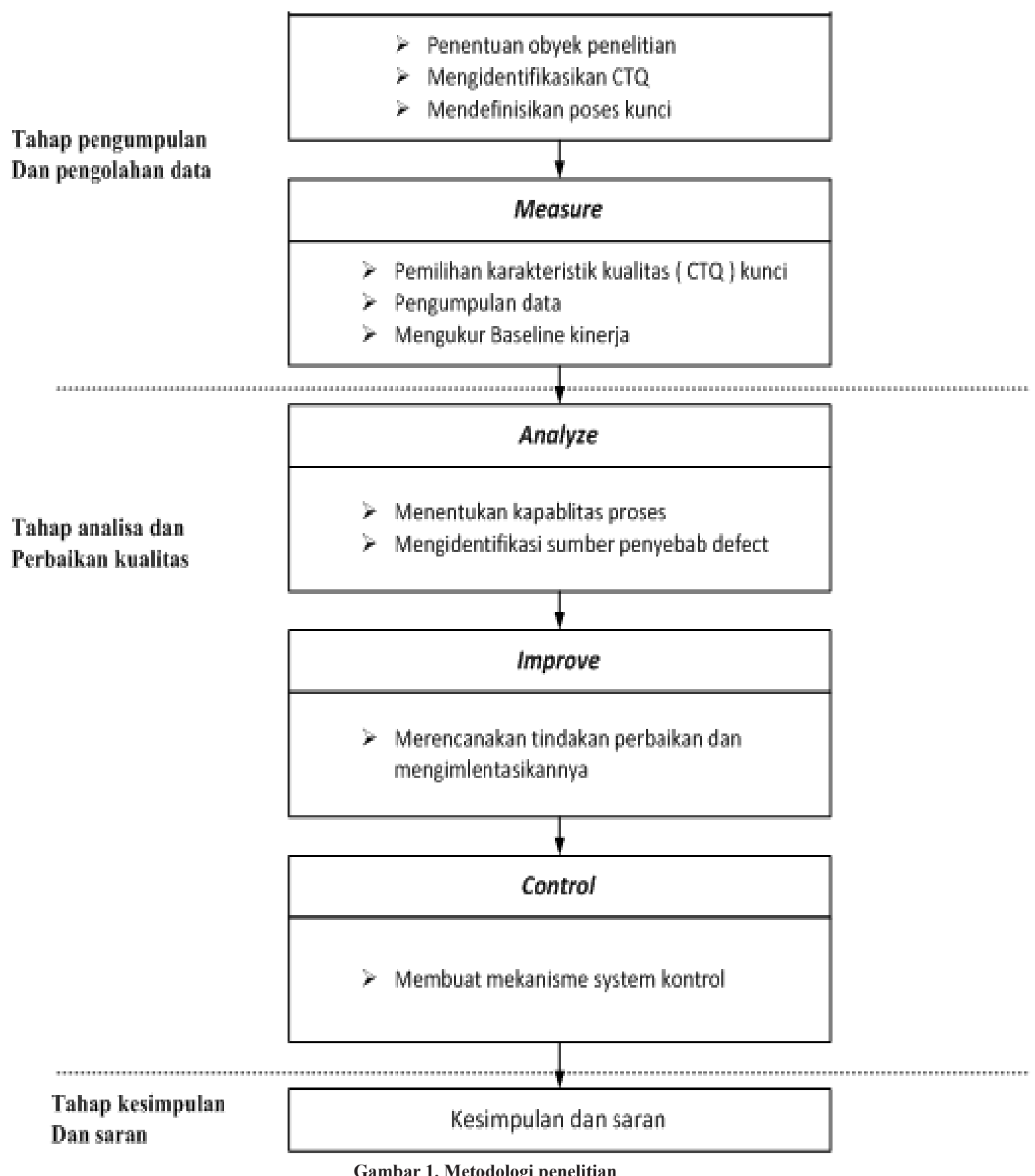

Gambar 1. Metodologi penelitian

\section{HASIL DAN PEMBAHASAN}

\section{Fase pendefinisian ( Define)}

Setiap produk memiliki karakteristik kualitas yang berbeda beda sesuai dengan standar tertentu yang telah di tetapkan. Demikian pula pada bagian atas produk Good day Cappucinno yang di produksi oleh PT.SANTOS JAYA ABADI yang menjadi focus penelitian tugas akhir ini, tentunya juga mempunyai karakteristik kualitas tersendiri. Berdasarkan metode yang di lakukan terhadap pihak manajemen perusahaan di tetapkan beberapa karakteristik kualitas tertentu yang ditemukan pada setiap proses maupun sub proses produksi Good day Cappucinno. Adapun karakteristik kualitas produk (CTQ) yang di hasilkan oleh setiap prosesnya dapat di bagi menjadi 2 ( dua ) bagian sesuai dengan jumlah proses produksinya,yaitu sub proses mixing dan packing seperti yang di tunjukkan pada tabel : 
Tabel 1 Karakteristik ( CTQ ) dari produk Good day Cappucinno

\begin{tabular}{|c|c|c|c|}
\hline Proses & Sub proses & Karakteristik CTO & Kriteria cacat \\
\hline \multirow[t]{2}{*}{ Mixing } & \multirow[t]{2}{*}{ Mixing } & $\begin{array}{l}\text { Tingkat kerataan dari tiap } \\
\text { bubuk campuran Good } \\
\text { day Cappucinno }\end{array}$ & Campuran tidak rata \\
\hline & & $\begin{array}{l}\text { Kesesuaian rasa } \\
\text { Kontaminasi benda asing }\end{array}$ & $\begin{array}{l}\text { Rasa tidak sesuai standar } \\
\text { Kontaminasi benda asing }\end{array}$ \\
\hline \multirow{3}{*}{ Packing } & \multirow{2}{*}{$\begin{array}{l}\text { Packing } \\
\text { (Inspeksi }\end{array}$} & $\begin{array}{l}\text { Kesesuaian Exp. Date } \\
\text { Kualitas potongan sachet }\end{array}$ & $\begin{array}{l}\text { Nomor Exp. Date tidak sesuai } \\
\text { Gembos }\end{array}$ \\
\hline & & $\begin{array}{l}\text { Kualitas sealing } \\
\text { Kesesuaian }\end{array}$ & $\frac{\text { Sealing tidak rata / bocor }}{\text { Berat terlalu maximal }}$ \\
\hline & $\begin{array}{c}\text { Visual dan } \\
\text { berat) }\end{array}$ & timbangan & minimal \\
\hline
\end{tabular}

Sumber : Data diolah

\section{Fase pengukuran (Measure)}

Tahap measure ini merupakan langkah operasional kedua dalam peningkatan kualitas six sigma. Pada tahap ini akan di lakukan penetapan atau pemilihan karakteristik $C T Q$ yang berhubungan langsung dengan kebutuhan pelanggan, mengembangkan rencana pengumpulan data melalui pengukuran yang di lakukan pada tingkat proses untuk di tetapkan sebagai baseline kinerja ( performance baseline) pada awal proyek six sigma.

Setelah di lakukan proses penetapan atau pemilihan karakteristik kualitas kunci ( $C T Q$ ), maka tahap berikutnya adalah menetapkan rencana untuk mengumpulkan data yang di lakukan

pada tingkat proses. Data yang di gunakan dalam penelitian ini adalah data atribut berupa data cacat produk yang merupakan data histories perusahaan, yang di dapatkan selama proses produksi.

Data atribut ini meliputi data kecacatan yang terjadi pada setiapproses maupun sub proses. Pengambilan data histories perusahaan untuk data atribut ini telah di tentukan berdasarkan kondisi dan kebijaksanaan dari manajemen perusahaan. Hasil pengumpulan data secara lengkap dapat di lihat sebagai berikut :

Tabel 2.Jumlah Mixing dan penolakan pada proses produksi Good day Cappucinno Periode Januari s.d April 2011

\begin{tabular}{|c|c|c|c|c|c|c|}
\hline \multirow{2}{*}{\multicolumn{2}{|c|}{ Periode }} & \multirow{3}{*}{$\begin{array}{r}\text { Jumlah } \\
\text { Mixing } \\
61\end{array}$} & \multirow{3}{*}{$\begin{array}{c}\begin{array}{c}\text { Jumlah } \\
\text { penolakan }\end{array} \\
3 \\
\end{array}$} & \multicolumn{3}{|c|}{ Jenis penolakan } \\
\hline & & & & \multirow{2}{*}{$\begin{array}{ll}\begin{array}{l}\text { Campuran tdk } \\
\text { rata }\end{array} \\
\end{array}$} & \multirow{2}{*}{$\begin{array}{r}\begin{array}{c}\text { Rasa tdk } \\
\text { standart }\end{array} \\
1\end{array}$} & \multirow{2}{*}{$\begin{array}{l}\text { Kontaminasi } \\
\text { benda asing }\end{array}$} \\
\hline \multirow{5}{*}{ 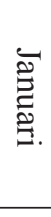 } & I & & & & & \\
\hline & II & 58 & 2 & 1 & 0 & 1 \\
\hline & III & 61 & 4 & 3 & 1 & 0 \\
\hline & IV & 55 & 2 & 1 & 1 & 0 \\
\hline & $\mathrm{V}$ & 61 & 5 & 3 & 2 & 0 \\
\hline \multirow{4}{*}{ 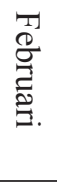 } & I & 61 & 4 & 1 & 3 & 0 \\
\hline & II & 61 & 3 & 1 & 2 & 0 \\
\hline & Ш & 62 & 2 & 1 & 1 & 0 \\
\hline & IV & 61 & 3 & 2 & 1 & 0 \\
\hline \multirow{5}{*}{$\begin{array}{l}3 \\
\mathbb{3} \\
\mathbb{3}\end{array}$} & I & 61 & 5 & 3 & 2 & 0 \\
\hline & II & 61 & 4 & 1 & 3 & 0 \\
\hline & Ш & 39 & 1 & 0 & 0 & 1 \\
\hline & IV & 61 & 0 & 0 & 0 & 0 \\
\hline & $\mathrm{V}$ & 61 & 2 & 2 & 0 & 0 \\
\hline & & & & & & \\
\hline
\end{tabular}




\begin{tabular}{|c|c|c|c|c|c|c|}
\hline \multirow{5}{*}{ 蛋 } & $\mathrm{I}$ & 39 & 3 & 1 & 1 & 1 \\
\hline & II & 58 & 0 & 0 & 0 & 0 \\
\hline & III & 61 & 3 & 2 & 1 & 0 \\
\hline & IV & 39 & 1 & 0 & 1 & 0 \\
\hline & $\mathrm{V}$ & 39 & 2 & 2 & 0 & 0 \\
\hline Total & & 1061 & 49 & 26 & 20 & 3 \\
\hline
\end{tabular}

Sumber : Data diolah

Tabel 3.Jumlah Produk cacat Good day Cappucinno Berdasakan jenis penolakan produk dalam satuan renteng ( 10 sachet) per minggu Periode Januari s.d April 2011

\begin{tabular}{|c|c|c|c|c|c|c|c|}
\hline & & & & & Jenis pen & kan produk & \\
\hline & & $\begin{array}{l}\text { Jumlah } \\
\text { produksi }\end{array}$ & $\begin{array}{l}\text { Jumlah } \\
\text { produk di }\end{array}$ & $\begin{array}{l}\text { Exp. } \\
\text { Date }\end{array}$ & Gembos & Sealingan & $\begin{array}{l}\text { Berat } \\
\text { tidak }\end{array}$ \\
\hline & I & 19500 & 218 & 40 & 33 & 42 & 103 \\
\hline & II & 18600 & 177 & 29 & 27 & 26 & 95 \\
\hline Januari & III & 19500 & 103 & 27 & 12 & 13 & 51 \\
\hline & IV & 17700 & 67 & 14 & 9 & 10 & 34 \\
\hline & V & 19500 & 107 & 18 & 7 & 31 & 51 \\
\hline & I & 19400 & 47 & 11 & 7 & 8 & 21 \\
\hline Februari & $\amalg$ & 19500 & 123 & 19 & 4 & 36 & 64 \\
\hline & Ш & 19800 & 134 & 17 & 10 & 42 & 65 \\
\hline & IV & 19500 & 74 & 14 & 11 & 13 & 36 \\
\hline & I & 19500 & 55 & 11 & 3 & 15 & 26 \\
\hline & $\amalg$ & 19500 & 76 & 13 & 5 & 29 & 29 \\
\hline Maret & III & 12600 & 30 & 6 & 4 & 9 & 11 \\
\hline & IV & 19500 & 119 & 23 & 15 & 21 & 60 \\
\hline & V & 19500 & 64 & 15 & 2 & 19 & 28 \\
\hline & I & 12600 & 324 & 61 & 4 & 70 & 189 \\
\hline & II & 18600 & 422 & 45 & 63 & 93 & 221 \\
\hline April & Ш & 19500 & 246 & 31 & 26 & 61 & 128 \\
\hline & IV & 12600 & 39 & 8 & 4 & 9 & 18 \\
\hline & $\mathrm{V}$ & 12600 & 74 & 19 & 6 & 18 & 31 \\
\hline & & & 2499 & 421 & 252 & 565 & 1261 \\
\hline
\end{tabular}

Pengukuran baseline kinerja untuk program peningkatan kualitas six sigma ini di lakukan dengan melakukan pengukuran pada tingkat proses dan sub proses. Dan agar pengukuran yang di lakukan terhadap baseline kinerja lebih teliti, serta untuk mencapai tujuan dari program peningkatan kualitas six sigma, maka juga di lakukan pengukuran tehadap baseline kinerja pada tiap tiap $C T Q$ yang di pilih menjadi focus dari penelitian ini. Dalam program peningkatan kualitas six sigma ini di tetapkan dengan menggunakan satuan pengukuran DPMO ( Defect Per Million Opportunities ) dan tingkat kapabilitas Sigma. Dari data hasil pengukuran produk cacat dari data di atas di tentukan baseline kinerja dari setiap proses dan sub-prosesnya.Adapun pengukuran baseline kinerja dapat di lihat pada tabe berikut :

Tabel 4. pengukuran baseline kinerja Periode Januari s.d April 2011

\begin{tabular}{|c|c|r|r|c|c|r|}
\hline Periode & Total & cacat & CTQ & DPO & DPMO & Nilai sigma \\
\hline \hline Januari s.d April 2011 & 17868 & 113 & 4 & 0,001630299 & 1630,30 & 4,44 \\
\hline
\end{tabular}




\begin{tabular}{|c|r|r|r|c|c|r|}
\hline Periode & Total Mixing & cacat & CTQ & DPO & DPMO & Nilai sigma \\
\hline Januaris.d April 2011 & 56 & 3 & 3 & 0,015294 & 15294,31 & 3,67 \\
\hline
\end{tabular}

\section{Fase Analisa (Analyze)}

Fase analyze merupakan fase mencari dan menetukan akar sebab dari suatu masalah. Masalah masalah yang timbul terkadang sangat kompleks sehingga kita bingung mana yang akan kita selesaikan.Diagram pareto dapat kita gunakan untuk memprioritaskan masalah yang harus di tangani dengan aturan pengelompokkan 80-20. Selanjutnya akar utama suatu permasalahan dapat di analisis menggunakan diagram cause and effect yang akan mem breakdown secara detail sebab sebab suatu masalah.

Berdasarkan diagram pareto jenis cacatyang menduduki urutan pertama adalah pada sub proses mixing yaitu campuran tidak rata ( 26 campuran atau 53,1\%), posisi kedua adalah rasa tidak sesuai standart ( 20 campuan atau $40,8 \%$ ) dan posisi ketiga adalah kontaminasi benda asing ( 3 campuran atau $6,1 \%$ ) sedangkan pada sub proses packing jenis cacat yang menduduki urutan pertama adalah berat tidak sesuai standart ( 1261 renteng atau 50,5\%), posisi kedua adalah sealingan jelek ( 565 renteng atau 22,6\%), posisi ketiga adalah Expt.date tidak sesuai standart ( 421 renteng atau $16,8 \%$ ) dan posisi ke empat adalah Gembos ( 252 renteng atau 10,1\%)

Setelah di lakukan brainstorming dengan pihak manajemen, maka secara garis besar di ketahui apa saja sumber sumber penyebab dari cacat produk yang dapat di tunjukkan dalam sebuah diagram sebab akibat (cause and effect).

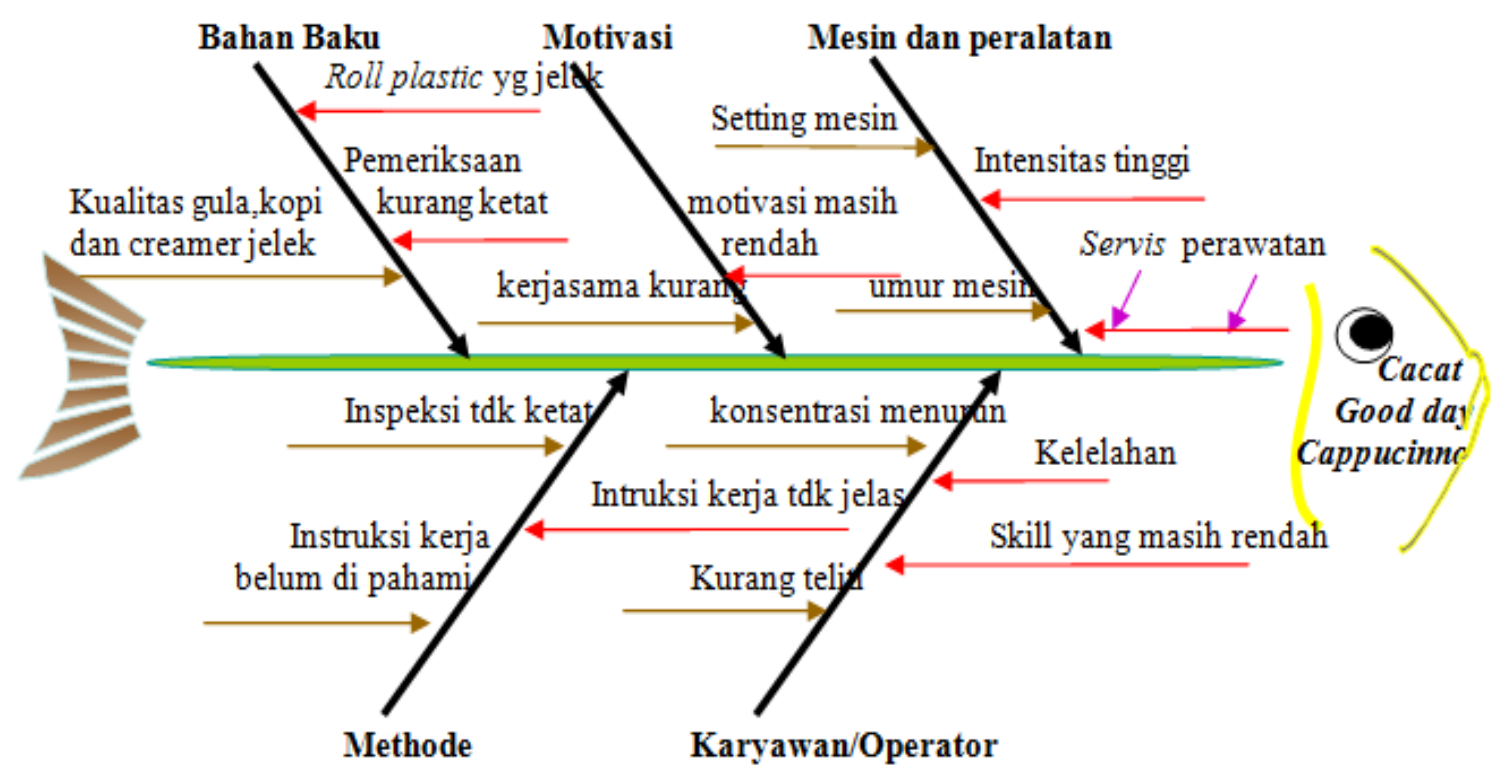

Gambar 1. Diagram sebab akibat (Cause and effect)

Berdasarkan diagram sebab akibat (cause and effect) di atas, sumber sumber penyebab cacat pada proses mixing dan packing secara umum terdiri dari Man ( manusia), Matherial (bahan baku), Motivation (motivasi), Machine (mesin) dan peralatan, Method (metode) Untuk mengetahui sumber sumber dan penyebab permasalahan kualitas produk pada masing masing proses dan sub proses produksinya,maka akan di lakukan analisa dengan methode FMEA.yaitu dengan cara menemukan semua variable penyebab cacat dari masing masing proses dan sub proses. Setelah di ketahui nilai kapabilitas sigma dari masing masing proses maupun sub proses, maka di lakukan brainstorming dengan pihak manajemen untuk menentukan kemungkinan apa yang menyebabkan kapabilitas sigma dari suatu proses maupun sub proses sangat rendah dan apa akar dari permasalahannya sehingga nantinya dapat tersusun suatu rencana peningkatan kualitas (action plan) untuk dapat menghilangkan dan mengurangi sumber permasalahan tersebut sehingga dapat 
meningkatkan nilai kapabilitas sigma dari masing masing proses maupun sub proses

\section{Fase meningkatkan ( Improve)}

Pada tahap perbaikan (improve) akan di buat rencana tindakan perbaikan dan peningkatan (action plan) untuk menghilangkan akar akar penyebab dan mencegah penyebab penyebab dapat terjadi kembali pada proses produksi yang akan di lakukan.Dari hasil analisa sebelumnya di ketahui semua penyebab terjadinya cacat serta prioritas cacat yang akan di lakukan perbaikan dan peningkatan.

Setelah sumber - sumber penyebab dari masalah teridentifikasi, maka perlu dilakukan rencana tindakan perbaikan yang akan diwujudkan dalam bentuk usulan tindakan perbaikan untuk melaksanakan program peningkatan kualitas Six Sixma. Tool yang akan digunakan dalam usulan tindakan perbaikan adalah Failure Mode and Effect Analyze (FMEA).tujuanya yaitu untuk mengetahui nilai $R P N$. Nilai $R P N$ (Risk Priority Number) dapat diperoleh yaitu dengan formulasi sebagai berikut: Severity x Occurance x Detecbility

FMEA dilakukan dengan cara brainstorming dengan pihak perusahaan yaitu pada bagian Departemen Produksi, karena departemen ini merupakan pihak yang berkompetensi dan mengetahui proses yang baik. Berdasarkan perhitungan FMEA, maka usulan prioritas tindakan perbaikanya dapat dilihat pada table berikut:

Tabel 5. Usulan prioritas tindakan perbaikan berdasarkan FMEA

\begin{tabular}{|c|c|l|}
\hline Priority & Risk Priority Number & $\begin{array}{l}\text { Usulan tindakan perbaikan } \\
\text { Memberikan peringatan pada karyawan agar tidak melakukan } \\
\text { kesalahan dalam mengontrol }\end{array}$ \\
\hline 2 & 320 & Menempatkan karyawan sesuai keahliannya \\
\hline 3 & 256 & $\begin{array}{l}\text { Memberikan training pada karyawan untuk memperbaiki hasil } \\
\text { kinerja }\end{array}$ \\
\hline 4 & 256 & Ditetapkan kestabilan proses mixing dan packing \\
\hline 6 & 256 & $\begin{array}{l}\text { Memberikappengarahan oleh supevisor pada karyawan } \\
\text { maupun packing agar lebih berhati - hati }\end{array}$ \\
\hline 7 & 256 & $\begin{array}{l}\text { Dilakukan pengecekan secara ketat setiap material datang } \\
\text { Dilakukan pengecekan komposisi material sesuai dengan } \\
\text { standart }\end{array}$ \\
\hline 8 & 256 & $\begin{array}{l}\text { Dilakukan pengecekan level control setiap sebelum proses } \\
\text { produksi }\end{array}$ \\
\hline 9 & 252 & $\begin{array}{l}\text { Melakukan perawatan dan pembersihan mixer maupun mesin } \\
\text { packing secara preventif }\end{array}$ \\
\hline 10 & 224 &
\end{tabular}

Sumber : Data diolah

Setelah di lakukan tindakan perbaikan terhadap penyebab potensial terjadinya cacat produk pada 2 ( dua ) sub-proses yang di prioritaskan, kemudian di lakukan target dari perusahaan untuk mencapai level sigma yang lebih tinggi. Adapun target yang di prioritaskan oleh perusahaan adalah 5 sigma, mengingat untuk mencapai tingat 6 sigma memerlukan waktu dan perbaikan secara terus. Adapun hasil pengukurannya adalah sebagai berikut :

Tabel 6. Scorecard sampai dengan bulan mei 2011

\begin{tabular}{|c|c|r|r|r|r|r|}
\hline \multirow{2}{*}{$\begin{array}{c}\text { Performance } \\
\text { metrics }\end{array}$} & \multirow{2}{*}{ parameter } & \multirow{2}{*}{ Target } & \multicolumn{4}{|c|}{ SCHEDULE } \\
\cline { 4 - 7 } & & & \multicolumn{4}{|c|}{ MEI } \\
\cline { 4 - 7 } & & I & II & III & IV \\
\hline \multirow{2}{*}{$\begin{array}{c}\text { Sub proses } \\
\text { Mixing }\end{array}$} & DPO & 0,000621 & 0,014262 & 0,012224 & 0,009137 & 0,005868 \\
\cline { 2 - 7 } & DPMO & 621 & 14262 & 12224 & 9137 & 5868 \\
\cline { 2 - 7 } & Sigma & 4 & 3,69 & 3,75 & 3,86 & 4,02 \\
\hline \multirow{2}{*}{$\begin{array}{c}\text { Sub proses } \\
\text { Packing }\end{array}$} & DPO & 0,000233 & 0,000986 & 0,000736 & 0,000519 & 0,00035 \\
\cline { 2 - 7 } & DPMO & 233 & 986 & 736 & 519 & 350 \\
\cline { 2 - 7 } & Sigma & 5 & 4,6 & 4,68 & 4,78 & 4,89 \\
\hline \hline
\end{tabular}

Sumber : Data diolah 


\section{Fase pengawasan ( Control)}

Control merupakan tahap opersional terakhir dalam proyek peningkatan kualitas six sigma. Dalam tahap ini di buat suatu mekanisme system control proses baik itu untuk mengontrol standar spesifikasi maupun untuk mengontrol instruksi kerja sehingga setiap proses dan sub-proses baik mixing maupun packing dapat di kendalikan agar cacat yang terjadi tidak akan terulang lagi serta kondisi kegagalan nol (zero defect) yang merupakan target dari peningkatan kualitas Six Sigma dapat tercapai.Alat yang paling umum di gunakan adalah diagram control.

\section{KESIMPULAN}

Aplikasi Six Sigma untuk meningkatkan kualitas penting dilakukan perusahaan agar peningkatan daya saing produk semakin baik dalam era yang semakin kompetitif dan dinamis ini. Aplikasi tersebut perlu ditunjang oleh adanya metode dan tools yang sistematis dan komprehensif agar pelaksanaan jalannya perbaikan berjalan dengan baik dan memenuhi target yang hendak dicapai seperti DMAIC, seven tools, dan FMEA.

Direkomendasikan, pelaksanaan perbaikan kualitas dengan Six Sigma perlu dilakukan secara serentak dan dilakukan penggambaran dan pendefinisian yang sistematis dan keseluruhan agar pemetaan permasalahan kualitas dapat terlihat secara menyuluruh. Usaha ini akan sangat membantu perusahaan didalam membentuk timtim Six Sigma di keseluruhan department dan line produksi. Adanya usaha ini akan menyebabkan lingkungan kerja akan semakin kondusif dan budaya "peduli kualitas" akan mudah terbentuk di perusahaan.

Dalam perbaikan Good day Cappucinno di PT Santos Jaya Abadi menunjukkan bahwa tidak semua rencana perbaikan mampu menurunkan DPMO atau meningkatkan nilai Sigma-nya mungkin karena pelaksanaan perbaikan di lapangan tidak berjalan dengan baik atau kurang efektif. Oleh karena itu penting bagi perusahaan melakukan evaluasi secara berkala untuk memastikan langkah pelaksanaan perbaikan di lapangan benar-benar berjalan dengan baik dan mengikuti prosedur yang telah direncanakan.

\section{DAFTAR PUSTAKA}

Brue, G., 2002, Six Sigma for Managers, Canary, Jakarta.

Emilasari, D., 2003, Sudi Perbaikan Kualitas terhadap Defect dengan Menggunakan Metode DMAIC di PT X, Tugas Akhir Jurusan Teknik Industri ITS.

Hendericks, C. and Kelbaugh, R., 1998, "Implementing Six Sigma at GE", The Journal for Quality and Participation, July/August.

Mayor, T., 2003, "Six Sigma comes to IT: targeting perfection", CIO Magazine, available at: www. cio.com/archive (accessed 24 January 2004).

Murphy, T., 1998, "Close enough to perfect", Ward's Auto World, Vol. 34 No. 8, August.

Paul, L., 1999, "Practice makes perfect", CIO Enterprise, Vol. 12 No. 7, Section 2, January 15. 